Dula, C. S., \& Ballard, M. E. (2003). Development and evaluation of a measure of dangerous, aggressive, negative emotional, and risky driving. Journal of Applied Social Psychology, 33(2): 263-282. (Feb 2003) Published by Wiley-Blackwell (ISSN:1559-1816). DOI: 10.1111/j.1559-1816.2003.tb01896.x The definitive version is available at www3.interscience.wiley.com

\title{
Development and Evaluation of a Measure of Dangerous, Aggressive, Negative Emotional, and Risky Driving
}

Chris S. Dula and Mary E. Ballard

\begin{abstract}
The Dula Dangerous Driving Index (DDDI) was created to measure drivers' self-reported likelihood to drive dangerously. Each DDDI scale (DDDI Total, Aggressive Driving, Negative Emotional Driving, and Risky Driving scales) had strong internal reliability and there was also evidence for the construct validity of the scales. The DDDI was used to examine the relation between dangerous and aggressive driving and dispositional aggression and anger among 119 college students. Males reported significantly more aggressive, risky, and angry driving than did females. Males and females reported similar levels of dangerous driving and negative emotions while driving. Dangerous driving was positively related to traffic citations and causing accidents. The DDDI will be useful as a research instrument to examine dangerous driving.
\end{abstract}


Public uneasiness over driver aggression has risen over the past several years, as it has become an increasingly familiar danger on international roadways (e.g., James \& Nahl, 2000; U.S. Department of Transportation [USDOT], 1998). Incidents of aggressive driving have risen 51\% since 1990 (Vest, Cohen, \& Tharp, 1997) and continue to rise about 7\% per year (Pepper, 1997). Aggressive driving often results in negative outcomes, such as property damage, injury, and death (e.g., Martinez, 1997; Mizell, 1997).

Three aspects of driving behavior have been labeled as aggressive in the driving literature: (a) intentional acts of physical, verbal, or gestured aggression; (b) negative emotions (e.g., anger) while driving; and (c) risk taking. In testimony before Congress, Martinez (1 997), then director of the National Highway Traffic and Safety Administration (NHTSA), defined aggressive driving as "driving behavior that endangers, or is likely to endanger, people or property," including behaviors ranging from risky driving (e.g., running red lights, weaving in traffic) to violence (e.g., running another's vehicle off the road, confronting a driver with a weapon). The latter behaviors clearly fit into the class of behaviors viewed as aggressive in the general aggression literature, where aggression is defined as behavior intended to harm other living beings either physically or psychologically (e.g., Baron \& Richardson, 1994; Berkowitz, 1998; Geen, 1998). The former behaviors, while not always aggressive in terms of intent to harm, are risky and often motivated by a disregard for others or hostility. We studied dangerous driving in terms of aggressive driving, negative emotions while driving, and risky driving.

Mizell (1997) provided an illustration of the level of damage caused by aggressive driving. Over a 6-year period, Mizell collected data on aggressive driving incidents, culled from 30 major newspapers, records of 16 police departments, and a variety of insurance claim reports. Mizell stringently defined aggressive driving as an incident in which a motorist intentionally attacked another motorist, passenger, or pedestrian in response to a traffic dispute, with the intention of killing or harming the other person. The number of aggressive driving incidents increased each year. A total of 10,037 aggressive driving incidents resulted in 218 murders and 12,610 injuries, many of them serious. Often, more than one person was injured in an aggressive driving episode (Mizell, 1997). Martinez (1997), drawing from a more comprehensive NHTSA data set, but using the less rigorous definition of driver aggression cited earlier, estimated that 27,650 deaths, hundreds of thousands of injuries, and $\$ 50$ billion in crashrelated costs were the result of aggressive driving on American roads in 1996 alone.

Two telephone surveys of Washington, DC, Beltway drivers indicated that from 1994 to 1997, substantially more drivers reported that they viewed aggressive driving as a factor in automobile crashes (USDOT, 1998). Only 2\% of a 1994 sample of Beltway drivers $(N=64)$ cited driver aggression as one of the three top causes of automobile crashes, while $38 \%$ of a 1997 sample $(N=52)$ perceived this to be the case. Researchers divided the 1997 sample into general $(N=32)$ and aggressive $(N=20)$ driver groups (most of the behaviors examined were risky, not aggressive in the classic sense). A majority (53\%) of general drivers believed driver aggression to be a main cause of crashes, compared to only $15 \%$ of aggressive drivers. General drivers named driver aggression as their primary 
roadway safety concern. Aggressive drivers reported frequent frustration and anger with other drivers and often blamed other drivers €or causing them to drive in a risky manner. Aggressive drivers were more likely than were general drivers to report competing with other drivers for position, speeding, "racing" away from stoplights, and intentionally blocking drivers who were trying to pass or change lanes (USDOT, 1998).

These findings are consistent with the position that driver aggression is related to an individual's dispositional level of aggression (Subcommittee on Surface Transportation Hearing, 1997). Levels of aggression are relatively stable from childhood through adulthood, especially among males (e.g., Eron \& Huesmann, 1990). Based on a 22-year longitudinal study, researchers concluded that individual differences in aggression are manifested early and predict the later experience and expression of aggression across situations (Eron, 1987; Huesmann, Eron, Lefkowitz, \& Walder, 1984). The relation between dispositional aggression and behavioral aggression across contexts has been substantiated among adolescents (Vance, Fernandez, \& Biber, 1998) and undergraduate students (Driscoll, Jarman, \& Yankeelov, 1994). Directly related to this study, aggression during childhood was positively correlated with driving citations in adulthood (Huesmann et al., 1984). Thus, it is likely that dispositional aggression predicts behavioral aggression in driving contexts.

Joint (1995) postulated that for most people, frustrating situations often arise when driving, and subsequent anger, aggression, or both are likely reactions. This is consistent with Berkowitz's (1 998) revised frustration-aggression hypothesis, which posits that agitated negative affect might result in aggression, given previous related experience (e.g., modeling) and concurrent negative appraisal of the situation. Theoretically and empirically, there is a strong link between negative emotions and aggression (e.g., Archer, Kilpatrick, \& Bramwell, 1995; Berkowitz, 1998; Canary, Spitzberg, \& Semic, 1998; Huesmann, 1998; O'Laughlin \& Schill, 1994), although cognitive processing and situational variables moderate these effects (e.g., Anderson \& Dill, 2000; Geen, 1998; Lajunen \& Parker, 2001). For example, male undergraduates with a history of aggression most commonly cited angedrevenge as their primary motive for interpersonal aggression (Pfefferbaum \& Wood, 1994).

In terms of driver aggression, Lajunen and Parker (2001) found that the relationship between driver anger and driver aggression was moderated by situational variables, such as the perceived intentions and recklessness of other drivers. Ellison-Potter, Bell, and Deffenbacher (200 1) did not find that self-reported driving anger influenced the likelihood of aggressive driving during a simulated driving run. However, they did not examine general dispositional anger in terms of aggressive driving.

Thus, individual differences and situational factors play a role in driver aggression. Social cognitive theories of aggression expand on this notion, suggesting that cognitive scripts (e.g., Geen, 1994; Huesmann, 1998), correspondence biases (e.g., Aronson, 1999; Epps \& Kendall, 1995; Gilbert \& Malone, 1995), and self-justification (e.g., Baumeister \& Boden, 1998) influence behavioral responses to aversive stimuli, like those found in daily driving situations. In addition, if drivers experience anonymity while driving (e.g., because of heavy 
traffic, the isolation of the vehicle, tinted windows, or lightly patrolled roads), the probability of aggression or risky behaviors increases (e.g., Aronson, 1999; Geen, 1994). Indeed, Ellison-Potter et al. (200 1) found that undergraduates drove a simulator more aggressively when they were anonymous and were exposed to aggressive stimuli (i.e., aggressive text on billboards and road signs).

Gender is another individual difference variable that might be related to driver aggression. Males are more likely than are females to report engaging in, and being the targets of, driver aggression (e.g., Ellison-Potter et al., 2001 ; Joint, 1995; Mizell, 1997). However, research regarding gender differences in aggression must be interpreted with caution because of several limitations. First, one's own gender and the gender of others influence the perception of aggression (Bukowski, 1990; Campbell, 1999). Thus, males and females might be differentially likely to report aggressive behavior. Second, as aggression is stereotyped as a masculine behavior, it has been examined more systematically among males across species, perhaps to the end of underestimating its occurrence in females (Brain, 1999). Third, males and females might vary in "preferred" types of aggression: Males might be more physical or overt, and females might be more relational or covert (Crick, 1996). Fourth, gender differences in aggression are more robust under some contexts than others (Thor \& Holloway, 1984). Fifth, gender interacts with developmental status to affect aggression (Enomoto, 1 990; Humphreys \& Smith, 1987; Werner \& Crick, 1999).

\section{STATEMENT OF THE PROBLEM}

Dangerous driving-including aggressive driving, driving while experiencing negative emotions, and taking risks while driving-is of empirical and practical concern. We aim to create and evaluate a reliable and valid self-report measure of dangerous (aggressive, negative emotional, and risky angry) driving. A sound measure of dangerous driving behavior is necessary for empirical research into dnver aggression (e.g., to understand the differences and commonalties between driver aggression and risky driving) and for applied uses (e.g., clinical assessment and intervention, employment screening).

\section{SCALE DEVELOPMENT}

\section{Method}

\section{Participants}

In the initial phase of scale development, 12 female and 11 male undergraduates participated. They received extra credit for a psychology course. All participants were White and ranged in age from 18 to 28 years $(M=20)$. 


\section{Procedure}

A pilot measure of 96 items that were thought to be potentially related to driver aggression, negative emotions while driving, and risky driving was created based on research findings (e.g., Connell \& Joint, 1996; Joint, 1995; Mizell, 1997; USDOT, 1998), Congressional testimony (e.g., James, 1997; Larson, 1997; Martinez, 1997; Snyder, 1997), and anecdotal experiences. Participants signed an informed consent form, completed a demographic form, and rated the 96 pilot items on a 5-point Likert scale in terms of how strongly they associated each item with aggressive driving (e.g., $1=$ not at all aggressive to $5=$ extremely aggressive).

\section{Results}

Average ratings were calculated for each of the 96 pilot items, and a tripartite split ( $N=32$ items) was used to determine which items most strongly evidenced behaviors related to dangerous driving. We chose a tripartite split to create a measure of reasonable length with excellent face validity. The item "I play highly competitive and/or physical contact sports" was eliminated as irrelevant. The remaining 31 items comprised the Dula Dangerous Driving Index (DDDI; Appendix), which had excellent internal reliability (Spearman-Brown alpah $=.94$ ).

\section{THE PRESENT STUDY}

\section{Method}

\section{Statement of the Problem}

Following the development of the DDDI, we administered the measure to a larger sample (a) to demonstrate reliability and concurrent validity; and (b) to examine dispositional factors common to aggressive, negative emotional, and risky driving. We expected to find that those with greater dispositional aggression and anger would report more dangerous (aggressive, negative emotional, and risky) driving (e.g., Anderson \& Dill, 2000; Huesmann et al., 1984; James \& Nahl, 2000; Subcommittee on Surface Transportation Hearing, 1997). Specifically, we expected that scores on measures of dispositional anger and aggression would be significantly and positively correlated with, and account for a significant proportion of the variance in, dangerous driving scores. Based on other reports (e.g., Ellison-Potter et al., 2001; Joint, 1995; Mizell, 1997), we expected males to report more aggressive driving.

\section{Participants}

Participants included 119 undergraduates (55 male, 62 female, 2 did not report gender) from Appalachian State University in western North Carolina. All received extra credit for a psychology course and were paid $\$ 1$ for their participation. 
They ranged in age from 18 to 36 years $(M=19.7)$. Most $(N=115)$ participants were White, while 1 was Hispanic/Latin and 1 was Asian/Oriental, 2 participants did not report ethnic background. Based on family income, participants' socioeconomic status was predominantly upper-middle class.

\section{Measures}

A demographic questionnaire was used to gather information on age, gender, ethnicity, estimated grade point average, years of driving experience, total number of tickets received in the last 2 years (excluding safety-belt violations), total number of crashes caused stress level on the day of participation, and overall stress level (both of the latter were measured on 9-point Likert scales). The 31item DDDI was administered to assess driver aggression, negative emotions related to driving, and risky driving behavior.

The Propensity for Angry Driving scale [3] (PADS; DePasquale, Geller, Clarke, \& Littleton, 200 1) was administered to assess angry driving behavior and to examine the convergent validity of the DDDI. The PADS consists of 22 hypothetical driving situations (e.g., "You are driving on a single lane road. For no apparent reason, the car in front of you is constantly braking and accelerating, cawing you to drive in the same manner. How do you respond?"). Participants select one of four responses, weighted for relative aggressiveness, for each scenario (e.g., "Slow down a little and keep a safe distance" or "Deliberately tailgate the car and occasionally lay on the horn"). Three items were distractors. The 19 scored items have high internal validity $(a p h a=89)$ and test-retest reliability $(r=$ .91; DePasquale et al., 2001).

The 133-item Interpersonal Behavior Survey Short Form (IBS; Mauger \& Adkinson, 1980) was used to assess participants' dispositional aggressiveness, assertiveness, and denial of socially undesirable traits. The IBS General Aggressiveness-Empirical scale measures dispositional aggression (e.g., "Some people think I have a violent temper"). The IBS General Assertiveness-Empirical scale measures assertiveness versus nonassertiveness (e.g., "I say what I want to say in most situations"). The IBS Denial scale measures participants' willingness to admit socially undesirable behaviors and minor flaws (e.g., "I never make fin of people who do things I feel are stupid"). The IBS also has subscales measuring anger expression (e.g., "I get mad easily"), physical aggression (e.g., "There are times when l'd like to pick fist fights"), and verbal aggression (e.g., "I usually tell people off when they disagree with me"). All of the IBS subscales have adequate validity (see Mauger \& Adkinson, 1980, for a review). Test-retest reliability for the subscales is excellent, and 10-week test-retest coefficients range from 31 to .93 (Mauger \& Adkinson, 1980).

Four subscales of the State-Trait Anger Expression Inventory (STAXI; Spielberger, 1996) were used to measure participants' anger and expression of hostility toward others. The Trait Anger scale served as a measure of dispositional anger. The Trait Anger scale measures participants' experience of anger, frustration, and unfairness. It has two subscales: the Angry Temperament subscale, and the Angry Reaction subscale. High angry temperament scores are 
related to lack of anger control (e.g., "I have a fiery temper"). High angry reaction scores are related to overreacting to perceived injustices or criticism from others (e.g., "I get angry when I'm slowed down by others' mistakes"). The Anger-Out scale measures the use of verbal and physical aggression (e.g., "I make sarcastic remarks to others"). Each scale has good reliability ( $a=.74$ to 34) and validity (Spielberger, 1996).

\section{Procedure}

Groups of 5 to 25 participants were run together. They were spaced around a large classroom so they could complete the surveys with relative privacy. Each participant signed an informed consent form and was given a packet containing the DDDI, PADS, IBS, STAXI, and the demographic form. The order of the measures was counterbalanced across packets. Participants were asked to follow written instructions, included in the packet, for each measure. Participants completed the procedure in 30 to 60 min, and were thanked given an extra credit slip, and paid \$1.

\section{RESULTS}

\section{Scale Refinement}

Based on item content and feedback from expert reviewers, the 31 DDDI items were divided into three categorical subscales: (a) aggressive driving (7 items reflecting behaviors intentionally meant to annoy, irritate, or punish other drivers; $a=.84$ ); (b) negative emotional driving (9 items gauging irritability and anger while driving and the tendency to be become annoyed with other drivers; $a=.85$ ); and (c) risky driving (12 items gauging willingness to engage in unsafe driving behaviors; $a=33$; see the Appendix for a list of all DDDI and subscale items). Subscale scores have the following possible ranges: aggressive driving = 7 to 35; negative emotional driving $=9$ to 45; and risky driving $=12$ to 60. DDDI Total scores $(a=.92)$ were the sum of the 28 subscale items and ranged from 28 to 140 . The following 3 DDDI items were excluded: "If another driver seriously threatened my safety, 1 would defend myself" was omitted because of its very high base rate $(M=4.1)$; "I am an aggressive driver" was omitted because of its subjectivity; and "I keep some type of weapon in my car/truck" was omitted because the item was not tied to driving per se (i.e., the weapon might be for hunting or for protection).

\section{Gender Differences and Similarities}

Males scored significantly higher than did females on the DDDI Aggressive Driving and Risky Driving subscales and on the PADS (Table 1). Males and females did not differ significantly on DDDI Total or Negative Emotional Driving scores. Males did score significantly higher than did females on the IBS Assertiveness and Physical Aggression scales. Females had significantly higher 
scores on the STAXI Angry Temperament scale. There was a similar trend with regard to the IBS Anger Expression scale $(p=.053)$. There were no gender differences in age, number of years driving, having caused a crash, total number of crashes caused or traffic tickets.

Table 1

Statistical Values for Subscales by Gender

\begin{tabular}{lrrrrrr}
\hline & \multicolumn{2}{c}{ Male } & & \multicolumn{2}{c}{ Female } & \\
\cline { 2 - 3 } \cline { 7 - 7 } \multicolumn{1}{c}{ Subscale } & \multicolumn{1}{c}{$M$} & \multicolumn{1}{c}{$S D$} & & \multicolumn{1}{c}{$M$} & $S D$ & \\
\hline DDDI Total Score & 70.73 & 11.79 & & 65.68 & 13.74 & 1.84 \\
DDDI Aggressive Driving & 17.40 & 4.98 & & 15.26 & 5.62 & $2.19^{*}$ \\
DDDI Negative Emotion & 26.76 & 4.67 & & 26.53 & 6.15 & 0.23 \\
DDDI Risky Driving & 34.53 & 7.67 & & 31.19 & 7.96 & $2.21^{*}$ \\
PADS & 54.62 & 14.56 & & 46.47 & 13.88 & $3.08^{* *}$ \\
IBS Denial & 1.79 & 1.45 & & 2.13 & 1.57 & -1.20 \\
IBS General Assertiveness & 16.49 & 4.17 & & 14.52 & 4.26 & $2.50^{*}$ \\
IBS General Aggression & 10.38 & 4.03 & & 9.27 & 4.38 & 1.41 \\
IBS Anger Expression & 1.62 & 1.41 & & 2.24 & 1.97 & -1.96 \\
IBS Physical Aggression & 2.34 & 1.37 & & 1.48 & 1.28 & $3.42^{* * * *}$ \\
IBS Verbal Aggression & 4.91 & 2.28 & & 4.53 & 2.21 & 0.89 \\
STAXI Trait Anger & 18.64 & 4.09 & & 19.89 & 6.16 & -1.31 \\
STAXI Angry Temperament & 5.95 & 1.92 & & 7.15 & 3.00 & $-2.61^{* *}$ \\
STAXI Angry Reaction & 9.04 & 2.39 & & 9.03 & 2.59 & 0.01 \\
STAXI Anger Out & 17.18 & 3.09 & & 17.07 & 4.80 & 0.16 \\
\hline
\end{tabular}

Note . DDDI $=$ Data Dangerous Driving Index PADS $=$ Propensity for Angry Driving Scale; IBS = Interpersonal Behavior Survey Short Form; STAXI = State-Trait Anger Expression Inventory; $d f \mathrm{~s}$ ranged from 113 to 115 for all analyses.

${ }^{*} p \leq .05,{ }^{* *} p \leq .01 .{ }^{* * *} p \leq .001$.

\section{Correlations}

Each DDDI (Total, Aggressive Driving, Negative Emotional Driving, and Risky Driving) score and the PADS score were significantly and positively correlated with all IBS and STAXI aggression and anger subscales and negatively correlated with the IBS Denial scale (Table 2). There were significant, positive correlations between each of the driver scales. Each driver scale was significantly, positively correlated to the number of traffic tickets received in the past 2 years (Table 3). DDDI Total scores and DDDI Risky Driving scores were significantly related to having caused a crash and to the total number of crashes caused. The DDDI Risky Driving subscale was also significantly, negatively related to age and number of years driving. 
Table 2

Pearson Product-Moment Correlations Between the Subscales

\begin{tabular}{|c|c|c|c|c|c|}
\hline Subscale & $\begin{array}{c}\text { DDDI } \\
\text { Total }\end{array}$ & $\begin{array}{c}\text { DDDI } \\
\mathrm{AD}\end{array}$ & $\begin{array}{c}\text { DDDI } \\
\text { NE }\end{array}$ & $\begin{array}{c}\text { DDDI } \\
\text { RD }\end{array}$ & PADS \\
\hline IBS Denial & $-.40^{* * * *}$ & $-.38 * * *$ & $-.34 * * *$ & $-.32 * * *$ & $-.26 * *$ \\
\hline $\begin{array}{l}\text { IBS General Aggression } \\
\text { IBS General }\end{array}$ & $.44 * * *$ & $.49^{* * *}$ & $.35^{* * *}$ & $.31 * * *$ & $.41 * * *$ \\
\hline Assertiveness & $.29 * *$ & $.32 * * *$ & .15 & $.28 * *$ & $.30 * * *$ \\
\hline IBS Anger Expression & $.38 * * *$ & $.36 * * *$ & $.46 * * *$ & $.19^{*}$ & $.32 * * *$ \\
\hline IBS Physical Aggression & $.31 * * *$ & $.32 * * *$ & $.20^{*}$ & $.27^{* *}$ & $.35 * * *$ \\
\hline IBS Verbal Aggression & $.38^{* * *}$ & $.43^{* * *}$ & $.31^{* * *}$ & $.26 * *$ & $.29 * * *$ \\
\hline STAXI Trait Anger & $.53^{* * *}$ & $.50 * * *$ & $.60^{* * *}$ & $.29 * * *$ & $.39 * * *$ \\
\hline STAXI Anger Out & $.47 * * *$ & $.55^{* * *}$ & $47^{* * *}$ & $.22^{*}$ & $.48^{* * *}$ \\
\hline STAXI Angry Reaction & $.49 * * *$ & $.45^{* * *}$ & $.55^{* * *}$ & $.28 * *$ & $.31 * * *$ \\
\hline $\begin{array}{l}\text { STAXI Angry } \\
\text { Temnerament }\end{array}$ & $39 * * *$ & $35 * * *$ & $51^{* *}$ & 17 & $34^{*}$ \\
\hline
\end{tabular}

Note. IBS = Interpersonal Behavior Survey Short Form; STAXI = State-Trait Anger Expression Inventory; DDDI $=$ Data Dangerous Driving Index; Total $=$ total score; $\mathrm{AD}=$ Aggressive Driving subscale; $\mathrm{NE}=$ Negative Emotion subscale; $\mathrm{RD}=$ Risky Driving subscale; PADS $=$ Propensity for Angry Driving Scale.

${ }^{*} p \leq .05,{ }^{* *} p \leq .01 .{ }^{* * *} p \leq .001$. 
Table 3

Pearson Product-Moment Correlations Between the Driving Subscales and Variables

\begin{tabular}{|c|c|c|c|c|c|c|c|c|c|c|c|}
\hline Subscale/variable & 1 & 2 & 3 & 4 & 5 & 6 & 7 & 8 & 9 & 10 & 11 \\
\hline 1. DDDI AD & - & $.77 * * *$ & $.55 * * *$ & $.88^{* * *}$ & $.76 * * *$ & $-.20^{*}$ & -.09 & -.13 & -.16 & .09 & $.23^{*}$ \\
\hline 2. DDDI NE & $.77^{* * * *}$ & - & $.52 * * *$ & $.87^{* * *}$ & $.65 * * *$ & -.02 & -.02 & -.06 & $-.19^{*}$ & .16 & $.22 *$ \\
\hline 3. DDDI RD & $.55^{* * * *}$ & $.52 * * *$ & - & $.83^{* * *}$ & $.44 * * *$ & $-.20^{*}$ & $-.19 *$ & $-.21 *$ & $-.38 * * *$ & $.33^{* * *}$ & $.37 * * *$ \\
\hline 4. DDDI Total & $.88^{* * *}$ & $.87^{* * *}$ & $.83^{* * *}$ & 一 & $.71^{* * *}$ & -.17 & -.12 & -.16 & $-.29 * * *$ & $.24 * *$ & $.33 * * *$ \\
\hline 5. PADS & $.76^{* * *}$ & $.65^{* * *}$ & $.44^{* * * *}$ & $.71^{* * *}$ & - & $-.28 * *$ & -.09 & -.13 & -.13 & .00 & $.22 *$ \\
\hline 6. Gender & $-.20^{*}$ & -.02 & $-.20 *$ & -.17 & $-.28 * *$ & - & .15 & .15 & .05 & .01 & -.05 \\
\hline 7. Age & -.09 & -.02 & $-.19^{*}$ & -.12 & -.09 & .15 & - & $.97^{* * * *}$ & .09 & -.10 & -.01 \\
\hline 8. Number of years driving & -.13 & -.06 & $-.21 *$ & -.16 & -.13 & .15 & $.97^{* * *}$ & - & .13 & -.12 & .00 \\
\hline 9. Ever caused a crash? & -.16 & $-.19 *$ & $-.38 * * *$ & $-.29 * * *$ & -.13 & .05 & .09 & .13 & - & $-.83^{* * *}$ & $-.29 * *$ \\
\hline $\begin{array}{l}\text { 10. Total number of } \\
\text { accidents caused } \\
\text { 11. Number of tickets } \\
\text { (past } 2 \text { years) }\end{array}$ & $.23^{*}$ & $.22 *$ & $.33^{* * *}$ & $.24 * *$ & .00 & .01 & -.10 & -.12 & $-.83^{* * *}$ & $.28 * *$ & $.28 * *$ \\
\hline
\end{tabular}

Note. DDDI $=$ Data Dangerous Driving Index $; \mathrm{AD}=$ Aggressive Driving subscale; $\mathrm{NE}=$ Negative Emotion subscale $; \mathrm{RD}=\mathrm{Risky}$ Driving subscale; PADS $=$ Propensity for Angry Driving Scale. Coding for Items 8 and 10: $1=$ Yes, $2=$ No. Coding for Item 6: $1=$ male, $2=$ female.

${ }^{*} p \leq .05,{ }^{* *} p \leq .01 .{ }^{* * *} p \leq .001$.

\section{Multiple Regression Analyses}

Four separate regression analyses were performed with each of the DDDI driver scales as the criterion variables. The IBS scales, STAXI scales, gender, age, and number of years driving were entered in a stepwise fashion as predictor variables. For DDDI total scores, the STAXI Trait Anger scale accounted for $26.9 \%$ of the variance, tickets in the last 2 years accounted for an additional $11.5 \%$ of the variance, and the IBS Denial scale and gender combined to account for an additional $8.4 \%$ of the variance (Table 4 ). 
Table 4

Summary of Predictor Variables Regressed Stepwise Onto DDDI Total Scores

\begin{tabular}{|c|c|c|c|c|c|c|}
\hline Model & $R$ & $R^{2}$ & Adj. $R^{2 \mathrm{a}}$ & $F$ & $p$ & $\begin{array}{c}\text { Unique } \\
\text { variance }\end{array}$ \\
\hline $\begin{array}{l}\text { Model } 1 \\
\text { (STAXI trait anger) }\end{array}$ & .525 & .276 & .269 & 41.85 & .00 & $27.1 \%$ \\
\hline $\begin{array}{l}\text { Model } 2 \\
\text { (Model } 1+\text { number of } \\
\text { tickets in last } 2 \text { years) }\end{array}$ & .628 & .395 & $.384(+11.5 \%)$ & 35.55 & .00 & $9.8 \%$ \\
\hline $\begin{array}{l}\text { Model } 3 \\
\text { (Model } 2+\text { IBS denial } \\
\quad \text { scale) }\end{array}$ & .671 & .450 & $.434(+5.0 \%)$ & 29.42 & .00 & $15.2 \%$ \\
\hline $\begin{array}{l}\text { Model } 4 \\
\text { (Model } 3+\text { gender) }\end{array}$ & .698 & .487 & $.468(+3.7 \%)$ & 25.43 & .00 & $2.0 \%$ \\
\hline \multicolumn{7}{|c|}{$\begin{array}{l}\text { Note. DDDI = Data Dangerous Driving Index; STAXI = State-Trait Anger Expression } \\
\text { Inventory; IBS = Interpersonal Behavior Survey Short Form. Total percentage of vari- } \\
\text { ance accounted for by all models }=46.8 \% \text {. The following variables were used as predic- } \\
\text { tors in the stepwise regression: IBS scales, all STAXI scales, gender, age, number of } \\
\text { years driving, number of accidents caused, and number of tickets. } \\
{ }^{a} R^{2} \text { increases incrementally with each additional model, where percentage increased } \\
\text { appears in parentheses. }\end{array}$} \\
\hline
\end{tabular}

Regarding DDDI Aggressive Driving scores, the STAXI Anger Out scale accounted for $29.5 \%$ of the variance, the IBS General Aggression scale accounted for $6.7 \%$ of the variance, the number of tickets in the last 2 years accounted for $5.1 \%$ of the variance, STAXI Angry Reaction scores accounted for $2.2 \%$ of the variance, and gender accounted for $2.3 \%$ of the variance (Table 5). DDDI Negative Emotional Driving scores were best explained by the STAXI Trait Anger scale, which accounted for $35.1 \%$ of the variance. Tickets received and the IBS Denial scores accounted for an additional $7.4 \%$ of the variance (Table 6). For DDDI Risky Driving scores, tickets received in the last 2 years accounted for $12.8 \%$ of the variance, while IBS General Aggression scores accounted for $10.2 \%$ of the variance, and the total number of accidents caused accounted for another $4.1 \%$ of the variance (Table 7 ). 
Table 5

Summary of Predictor Variables Regressed Stepwise Onto DDDI Aggressive Driving Scores

\begin{tabular}{|c|c|c|c|c|c|c|}
\hline Model & $R$ & $R^{2}$ & Adj. $R^{2 \mathrm{a}}$ & $F$ & $p$ & $\begin{array}{l}\text { Unique } \\
\text { variance }\end{array}$ \\
\hline $\begin{array}{l}\text { Model } 1 \\
\text { (STAXI anger out) }\end{array}$ & .549 & .302 & .295 & 47.52 & .00 & $29.3 \%$ \\
\hline $\begin{array}{l}\text { Model } 2 \\
\text { (Model 1 + IBS general } \\
\quad \text { aggression) }\end{array}$ & .611 & .373 & $.362(+6.7 \%)$ & 32.47 & .00 & $23.1 \%$ \\
\hline $\begin{array}{l}\text { Model } 3 \\
\text { (Model } 2+\text { number of } \\
\text { tickets in last } 2 \text { years) }\end{array}$ & .655 & .429 & $.413(+5.1 \%)$ & 27.00 & .00 & $4.5 \%$ \\
\hline $\begin{array}{l}\text { Model } 4 \\
\text { (Model } 3+\text { STAXI angry } \\
\quad \text { reaction) }\end{array}$ & .675 & .456 & $.435(+2.2 \%)$ & 22.38 & .00 & $19.9 \%$ \\
\hline $\begin{array}{l}\text { Model } 5 \\
\text { (Model } 4+\text { gender) }\end{array}$ & .694 & .482 & $.458(+2.3 \%)$ & 19.74 & .00 & $3.1 \%$ \\
\hline \multicolumn{7}{|c|}{$\begin{array}{l}\text { Note. DDDI = Data Dangerous Driving Index; STAXI = State-Trait Anger Expression } \\
\text { Inventory; IBS = Interpersonal Behavior Survey Short Form. Total percentage of vari- } \\
\text { ance accounted for by all models }=45.8 \% \text {. The following variables were used as predic- } \\
\text { tors in the stepwise regression: IBS scales, all STAXI scales, gender, age, number of } \\
\text { years driving, number of accidents caused, and number of tickets. } \\
{ }^{2} R^{2} \text { increases incrementally with each additional model, where percentage increased } \\
\text { appears in parentheses. }\end{array}$} \\
\hline
\end{tabular}


Table 6

Summary of Predictor Variables Regressed Stepwise Onto DDDI Negative Emotion Driving Scores

\begin{tabular}{|c|c|c|c|c|c|c|}
\hline Model & $R$ & $R^{2}$ & Adj. $R^{2 \mathrm{a}}$ & $F$ & $p$ & $\begin{array}{l}\text { Unique } \\
\text { variance }\end{array}$ \\
\hline $\begin{array}{l}\text { Model } 1 \\
\text { (STAXI trait anger) }\end{array}$ & .598 & .357 & .351 & 61.16 & .00 & $35.8 \%$ \\
\hline $\begin{array}{l}\text { Model } 2 \\
\text { (Model } 1+\text { number of } \\
\text { tickets in last } 2 \text { years) }\end{array}$ & .643 & .414 & $.403(+5.2 \%)$ & 38.50 & .00 & $3.9 \%$ \\
\hline $\begin{array}{l}\text { Model } 3 \\
\text { (Model 2 + IBS denial } \\
\quad \text { scale) }\end{array}$ & .664 & .440 & $.425(+2.2 \%)$ & 28.33 & .00 & $10.5 \%$ \\
\hline \multicolumn{7}{|c|}{$\begin{array}{l}\text { Note. DDDI = Data Dangerous Driving Index; STAXI = State-Trait Anger Expression } \\
\text { Inventory; IBS = Interpersonal Behavior Survey Short Form. Total percentage of vari- } \\
\text { ance accounted for by all models }=42.5 \% \text {. The following variables were used as predic- } \\
\text { tors in the stepwise regression: IBS scales, all STAXI scales, gender, age, number of } \\
\text { years driving, number of accidents caused, and number of tickets. } \\
\text { a } R^{2} \text { increases incrementally with each additional model, where percentage increased } \\
\text { appears in parentheses. }\end{array}$} \\
\hline
\end{tabular}


Table 7

Summary of Predictor Variables Regressed Stepwise Onto DDDI Risky Driving Scores

\begin{tabular}{|c|c|c|c|c|c|c|}
\hline Model & $R$ & $R^{2}$ & Adj. $R^{2 \mathrm{a}}$ & $F$ & $p$ & $\begin{array}{l}\text { Unique } \\
\text { variance }\end{array}$ \\
\hline $\begin{array}{l}\text { Model } 1 \\
\text { (number of tickets in last } \\
2 \text { years) }\end{array}$ & .368 & .136 & .128 & 17.28 & .00 & $12.8 \%$ \\
\hline $\begin{array}{l}\text { Model } 2 \\
\text { (Model 1 + IBS general } \\
\quad \text { aggression) }\end{array}$ & .493 & .243 & $.230(+10.2 \%)$ & 17.54 & .00 & $9.0 \%$ \\
\hline $\begin{array}{l}\text { Model } 3 \\
\text { (Model } 2+\text { number of } \\
\quad \text { accidents caused) }\end{array}$ & .539 & .291 & $.271(+4.1 \%)$ & 14.76 & .00 & $10.2 \%$ \\
\hline
\end{tabular}

Note. DDDI $=$ Data Dangerous Driving Index; IBS $=$ Interpersonal Behavior Survey Short Form; STAXI = State-Trait Anger Expression Inventory. Total percentage of variance accounted for by all modeis $=27.1 \%$. The following variables were used as predictors in the stepwise regression: IBS scales, all STAXI scales, gender, age, number of years driving, number of accidents caused, and number of tickets.

${ }_{a} R^{2}$ increases incrementally with each additional model, where percentage increased appears in parentheses.

\section{GENERAL DISCUSSION}

We accomplished two goals with this project. First, we developed a reliable and valid measure of dangerous driving and driver aggression that will be useful in empirical and applied settings. Second, we supported the hypothesis that levels of dispositional anger and aggression would be correlated positively with dangerous and aggressive driving. Further, measures of anger and aggression accounted for a significant amount of the variance in DDDI subscale scores.

The data were consistent with evidence that people with higher levels of dispositional anger and aggression are more likely to display anger and aggressive behaviors across a variety of situations and are more likely to be aggressive drivers (e.g., Archer et al., 1995; Epps \& Kendall, 1995; James \& Nahl, 2000; O'Laughlin \& Schill, 1994; Pfefferbaum \& Wood, 1994; Subcommittee on Surface Transportation Hearing, 1997). The strong correlations between DDDI scores and driving outcomes (number of tickets, causing accidents) indicate that rising concern over aggressive driving (e.g., Joint, 1995; USDOT, 1998) is legitimate as aggressive, drivers engage in behaviors that increase the chance of automobile crashes.

The data reveal significant negative correlations between each driving subscale and the IBS Denial scale. This finding indicates that social desirability 
might play a role in self-reports of driving behavior. However, denial is positively related to elevated narcissism (e.g., de Zulueta, 1996; Raskin, Novacek, \& Hogan, 1991). Thus, an element of narcissism might be present among dangerous and aggressive drivers. This would be consistent with Baumeister and colleagues' (Baumeister \& Boden, 1998; Bushman \& Baumeister, 1998) view that a highly favorable view of the self and an unfavorable external appraisal of others are the primary basis of aggression. Thus, future studies of driver aggression should include measures of narcissism and social desirability.

In terms of gender, males and females scored similarly on DDDI Total scores and DDDI Negative Emotional Driving. Thus, the experience of anger and frustration on the road was similar for males and females. However, our results are consistent with other data indicating higher levels of risky and aggressive driving among males (e.g., Joint, 1995; Mizell, 1997). Thus, while females were as likely as males to report becoming angry while driving, they were less likely to report overtly risky or aggressive driving. However, gender similarity in DDDI Total scores and self-report of crashes caused and tickets received indicates that male and female drivers do not differ substantially in terms of overall dangerous driving behavior.

There are at least two weaknesses of the current study that require consideration. First, the data are based on self-report, which has some inherent limitations. Second, the results were drawn from a small, homogeneous sample of undergraduates with relatively limited driving experience. Consequently, the conclusions might not generalize to other populations of drivers. However, given the nature of the constructs examined and the robust relations among relevant variables, we are reasonably certain that these results will be replicated in broader samples of drivers.

Our results provide a glimpse into the variables related to aggressive driving. Other factors (e.g., how aggressive driving scripts are developed and activated) must be explicated to understand aggressive driving (e.g., Aronson, 1999; Baumeister \& Boden, 1998; Berkowitz, 1998; Canary et al., 1998; Huesmann, 1998). This is particularly important among those high in dispositional aggression, as they have stronger, more easily elicited aggressive scripts and are more likely to assume aggressive intent on the part of another driver (e.g., Aronson, 1999; Bushman, 1996; Dill, Anderson, Anderson, \& Deuser, 1997), increasing the likelihood of an aggressive response (Aronson, 1999; Baumeister \& Boden, 1998; Berkowitz, 1998; Connell \& Joint, 1996; Dill et al., 1997; Huesmann, 1998; Joint, 1995; Mizell, 1997).

In sum, our results indicate that people higher in dispositional anger and aggression engage in higher levels of aggressive, angry, and risky driving. Further, the DDDI appears to be a viable tool to identify drivers who are likely to be more dangerous and aggressive than those in the general population. Thus, the scale should be useful in screening drivers for employment and for clinical intervention. Further research (e.g., Doob \& Gross, 1968; Ellison, Govern, Petri, \& Figler, 1995; Ellison-Potter et al., 2001; Hennessy \& Wiesenthal, 1999) should be conducted to examine if drivers who are categorized as more dangerous actually engage in more real-world aggressive, risky, and negative emotional driving. 


\section{FOOTNOTES}

3. After initiating development of the DDDI, we found that a team of researchers at Virginia Tech (DePasquale, Geller, Clarke, \& Littleton, 2001) was developing a contextual measure of driver aggression termed the Propensity for Angry Driving scale (PADS). Thus, we added the PADS as a measure of driver aggression and a test of convergent validity for the DDDI.

\section{REFERENCES}

Anderson, C. A., \& Dill, K. E. (2000). Video games and aggressive thoughts, feelings, and behavior in the laboratory and in life. Journal of Personality and Social Psychology, 78, 112-190.

Archer, J., Kilpatrick, G., \& Bramwell, R. (1 995). Comparison of two aggression inventories. Aggressive Behavior, 21,371-380.

Aronson, E. (1999). The social animal (8th ed.). New York, NY Worth Publishers/ W. H. Freeman.

Baron, R. B., \& Richardson, D. (1994). Human aggression. New York, NY Plenum.

Baumeister, R. F., \& Boden, .I. M. (1998). Aggression and the self: High self-esteem, low self-control, and ego threat. In R. G. Geen \& E. Donnerstein (Eds.), Human aggression: Theories, research, and implications for social policy (pp. 11 1-137). San Diego, CA: Academic Press.

Berkowitz, L. (1 998). Frustration-aggression hypothesis: Examination and reformulation. Psychological Bulletin, 106, 59-73.

Brain, P. F. (1999). Aggression in female mammals: Is it really rare? Commentary on Campbell. Behavioral and Brain Sciences, 22,218.

Bukowski, W. M. (1 990). Age differences in children's memory of information about aggressive, socially withdrawn, and prosociable boys and girls. Child Development, 61, 1326-1334.

Bushman, B. J. (1996). Individual differences in the extent and development of aggressive cognitive-associative networks. Personality and Social Psychology Bulletin, 22, 81 1-8 19.

Bushman, B. J., \& Baumeister, R. F. (1998). Threatened egotism, narcissism, self-esteem, and direct and displaced aggression: Does self-love or self-hate lead to violence? Journal of Personality and Social Psychology, 75,2 19-229.

Campbell, A. (1 999). Staying alive: Evolution, culture, and women's intrasexual aggression. Behavioral and Brain Sciences, 22, 203-2 14. 
Canary, D. J., Spitzberg, B. H., \& Semic, B. A. (1998). The experience and expression of anger in interpersonal settings. In P. A. Anderson \& L. K. Guerrero (Eds.), Handbook of communication and emotion: Research, theory, applications, and contexts (pp. 189-213). San Diego, CA: Academic Press.

Connell, D., \& Joint, M. (1996, November). Driver aggression. AAA Foundation for Traffic Safety, Retrieved June 30, 1998, from http://www.aaafts.orgITextJ researchlagdrtext. htm

Crick, N. R. (1996). The role of overt aggression, relational aggression, and prosocial behavior in the prediction of children's future social adjustment. Child Development, 67,23 11-2321.

DePasquale, J. F!, Geller, E. S., Clarke, S. W., \& Littleton, L. C. (2001). Measuring road rage: Development of the Propensity for Angry Driving scale. Journal of Safity Research, 32, 1-1 6.

de Zulueta, F. (1996). Theories of aggression and violence. In C. Cordess \& M. Cox (Eds.), Forensicpsychotherapy: Crime, psychodynamics, and the offender patient: Vol. 1. Mainly theory (pp. 175-186). Bristol, PA: Jessica Kingsley.

Dill, K. E., Anderson, C. A., Anderson, K. B., \& Deuser, W. E. (1997). Effects of aggressive personality on social expectations and social perceptions. Journal ofResearch in Personality, 31,272-292.

Doob, A. N., \& Gross, A. E. (1968). Status of frustrator as an inhibitor of hornhonking responses. Journal of Social Psychology, 76,213-2 18.

Driscoll, J. M., Jarman, B. J., \& Yankeelov, P. A. (1994). Effects of a person's history of aggression on attributions of affect to aggressors. Journal of Social Behavior and Personality, 9,685-100.

Ellison, P. A., Govern, J. M., Petri, H. L., \& Figler, M. H. (1995). Anonymity and aggressive driving behavior: A field study. Journal of Social Behavior and Personality, 10,265-272.

Ellison-Potter, P., Bell, P.,, \& Deffenbacher, J. (2001). The effects of trait driving anger, anonymity, and aggressive stimuli on aggressive driving behavior. Journal of Applied Social Psychology, 31,43 1-443.

Enomoto, T. (1990). Social play and sexual behavior of the bonobo (Pan paniscus) with special reference to flexibility. Primates, 31,469-480.

Epps, J., \& Kendall, F? C. (1995). Hostile attributional bias in adults. Cognitive Therapy and Research, 19, 159-178.

Eron, L. D. (1987). The development of aggressive behavior from the perspective of a developing behaviorism. American Psychologist, 42,435-442.

Eron, L. D., \& Huesmann, L. R. (1990). The stability of aggressive behavior even unto the third generation. In M. Lewis \& s. M. Miller (Eds.), Handbook 
of developmental psychopathology: Perspectives in developmental psychology (pp. 147- 156). New York, NY Plenum. Geen, R. G. (1994). Aggression and antisocial behavior. In D. T. Gilbert, S. T.

Fiske, \& G. Lindzey (Eds.), The handbook of social psychology (Vol. 2,4th ed., pp. 3 17-356). Boston, MA: McGraw-Hill.

Geen, R. G. (1998). Processes and personal variables in affective aggression. In R. G. Geen \& E. Donnerstein (Eds.), Human aggression: Theories, research, and implications for social policy (pp. 1-21). San Diego, CA: Academic Press.

Gilbert, D. T., \& Malone, F? S. (1995). The correspondence bias. Psychological Bulletin, 117,21-38.

Hennessy, D. A., \& Wiesenthal, D. L. (1999). Traffic congestion, driver stress, and driver aggression. Aggressive Behavior, 25,409-423.

Huesmann, L. R. (1998). The role of social information processing and cognitive schema in the acquisition and maintenance of habitual aggressive behavior. In

R. G. Geen \& E. Donnerstein (Eds.), Human aggression: Theories, research, and implications for social policy (pp. 73-109). San Diego, CA: Academic Press.

Huesmann, L. R., Eron, L. D., Lefiowitz, M. M., \& Walder, L. O. (1984). Stability of aggression over time and generations. Developmental Psychology, 20,

Humphreys, A. I?, \& Smith, P. K. (1987). Rough-and-tumble, friendship, and dominance in schoolchildren: Evidence for continuity and change with age. Child Development, 58,201-212.

James, L. (1997, July 17). Testimony to House Transportation and Infrastructure Committee, Surface Transportation Subcommittee. Retrieved June 30, 1998, from http:Nwww.aloha.net/-dyc/testimony.html

James, L., \& Nahl, D. (2000). Road rage and aggressive driving: Steering clear of highway warfare. Amherst, Ny: Prometheus Books.

Joint, M. (1995, March). Road rage. AAA Foundation for Traffic Safety. Retrieved June 30, 1998, from http://www.aaafts.org/Text/research/agdrtext.htm

Lajunen, T., \& Parker, D. (2001). Are aggressive people aggressive drivers? A study of the relationship between self-reported general aggressiveness, driver anger, and aggressive driving. Accident Analysis and Prevention, 33,

Larson, J. A. (1997, July 17). Testimony to House Transportation and Infrastructure Committee, Surface Transportation Subcommittee. Retrieved June 30, 1998, from http://www.house.gov/transportation/surface/sthearin/ist177 /lmon.htm

Martinez, R. (1997, July 17). Testimony to House Transportation and Infrastructure Committee, Surface Transportation Subcommittee. Retrieved June 30, 1998, 
from http://www.house.gov/transportation/surface/sthearin/is1t717/martinez.h\& Mauger, P. A., \& Adkinson, D. R. (1980). Interpersonal Behavior Survey manual. Los Angeles, CA: Western Psychological Services.

Mizell, L. (1997). Aggressive driving. AAA Foundation for Traffic Safety. Retrieved June 30, 1998, from http://www.aaafts.org/Text/research/agdrtext.htm

O'Laughlin, S., \& Schill, T. (1994). The relationship between self-monitored aggression and the MMPI-2 F, 4,9 composite and anger content scale scores. Psychological Reports, 74, 733-734.

Pepper, M. (1997, April). What about road rage? US. News and World Report. Available at http:Ilwww.drivers.com/issues/roadrage/pepper.html

Pfefferbaum, B., \& Wood, P. B. (1994). Self-report study of impulsive and delinquent behavior in college students. Journal of Adolescent Health, 15,

Raskin, R., Novacek, J., \& Hogan, R. (1991). Narcissism, self-esteem, and defensive self-enhancement. Journal of Personality, 59, 19-3 8.

Snyder, D. F. (1997, July 17). Testimony to House Transportation and Infrastructure Committee, Surface Transportation Subcommittee. Retrieved June 30, 1998, from http://www.house.gov/transportation/surface/sthearinfist177 Isnyder.htm

Spielberger, C. D. (1 996). State-Trait Anger Expression Inventory professional manual. Odessa, FL: Psychological Assessment Resources.

Subcommittee on Surface Transportation Hearing. (1 997). Chairman Schuster welcomes hearing on aggressive driving (press release July 17, 1997). Retrieved June 30, 1998, from http://www.house.gov/transportation/surface/ sthearin/ist717/ist7 17.htm

Thor, D. H., \& Holloway, W. R., Jr. (1984). Sex and social play in juvenile rats (rattus norvegicus). Journal of Comparative Psychology, 98,276-284.

U.S. Department of Transportation, Preusser Research Group, Inc. (1 998, April). Capital Belt update: Beltway user focus group. National Roadway Traffic Safety Administration Report (DOT HS 808 705). Retrieved June 30, 1998, from http:Il .nhtsa.dot.gov/people/injury/aggressive/aggressive\%2Ocapital \%20beltwaylintroduction.html

Vance, J. E., Fernandez, G., \& Biber, M. (1998). Educational progress in a population of youth with aggressive and emotional disturbance: The role of risk and protective factors. Journal of Emotional and Behavioral Disorders, 6,2 14-22 1.

Vest, J., Cohen, W., \& Tharp, M. (1997, June). Road rage. US. News Online. Retrieved from http://www.drivers.coml issues/roadrage/2driv.htm

Werner, N. E., \& Crick, N. R. (1999). Relational aggression and social-psychological adjustment in a college sample. Journal of Abnormal Psychology, 108,615-623. 


\section{APPENDIX}

\section{Dula Dangerous Driving Index}

Note. Subscale items are denoted as follows: $A D=$ aggressive driving; $N E=$ negative emotions while driving; $\mathrm{RD}=$ risky driving; $0=$ item omitted from subscales. Participants responded to the items with the following Likert scale: $A=$ never, $\mathrm{B}=$ rarely, $\mathrm{C}=$ sometimes, $\mathrm{D}=$ often, $\mathrm{E}=$ always.

Participants received the following written directions: "Please answer each of the following items as honestly as possible. Please read each item carefully and then fill in the bubble/circle of the answer you choose on the form. If none of the choices seem to be your ideal answer, then select the answer that comes closest. THERE ARE NO RIGHT OR WRONG ANSWERS. Select your answers quickly and do not spend too much time analyzing your answers. You may change any answer(s) at any time before completing this form. If you do change an answer, please erase the previous mark(s) entirely."

1. I drive when I am angry or upset. (NE)

2. I lose my temper when driving. (NE)

3. I consider the actions of other drivers to be inappropriate or "stupid." (NE)

4. I flash my headlights when I am annoyed by another driver. (AD)

5. I make rude gestures (e.g., giving "the finger," yelling curse words) toward drivers who annoy me. (AD)

6. I verbally insult drivers who annoy me. (AD)

7. I deliberately use my car/truck to block drivers who tailgate me. (AD)

8. If another driver seriously threatens my safety, I would defend myself. (O)

9. I would tailgate a driver who annoys me. (AD)

10. I "drag race" other drivers at stop lights to get out front. (RD)

11. I will illegally pass a car/truck that is going too slowly. (RD)

12. I feel it is my right to strike back in some way, if I feel another driver has been aggressive toward me. (AD)

13. When I get stuck in a traffic jam, I get very irritated. (NE)

14. I will race a slow moving train to a railroad crossing. (RD)

15. I will weave in and out of slower traffic. (RD)

16. I will drive if I am only mildly intoxicated or buzzed. (RD)

17. When someone cuts me off, I feel I should punish him/her. (AD)

18. I get impatient and/or upset when I fall behind schedule when I am driving (NE)

19. Passengers in my car/truck tell me to calm down. (NE)

20. I get irritated when a car/truck in front of me slows down for no reason. (NE)

21. I will cross double yellow lines to see if I can pass a slow moving car/truck. (RD)

22. I feel it is my right to get where I need to go as quickly as possible. (RD)

23. I am an aggressive driver. (O)

24. I feel that passive drivers should learn how to drive or stay home. WE)

25. I keep some type of weapon in my car/truck. (O)

26. I will drive in the shoulder lane or median to get around a traffic jam. (RD)

27. When passing a car/truck on a 2-lane road, I will barely miss on-coming cars. (RD)

28. I will drive when I am drunk. (RD)

29. I feel that I may lose my temper if I have to confront another driver. (NE)

30. I consider myself to be a risk-taker. (RD)

31. I feel that most traffic "laws" could be considered as suggestions. (RD) 